\title{
INDUSTRY 4.0 AND TELECOLLABORATION TO PROMOTE COOPERATION NETWORKS: A PILOT SURVEY IN THE PORTUGUESE REGION OF CASTELO BRANCO
}

\author{
Mónica Martins de Andrade Régio ${ }^{1}$, Marcelo Rudolfo Calvete Gaspar², Lis Manuel do Carmo Farinha ${ }^{3}$, \\ Maria Margarida Afonso de Passos Morgado 4 \\ 1,2,3 Escola Superior de Tecnologia, Instituto Politécnico de Castelo Branco, \\ ${ }^{4}$ Escola Superior de Educação, Instituto Politécnico de Castelo Branco \\ monicaregio@ipcb.pt, calvete@ipcb.pt, luis.farinha@ipcb.pt \\ marg.morgado@ipcb.pt
}

\begin{abstract}
According to the World Economic Forum, the Fourth Industrial Revolution - also known as Industry 4.0 - is expected to take place before 2020 , fostering significant changes in the way people think, live and work. Impending changes will have great impact on people and businesses. Growing digital interconnectivity will promote new business contexts, fostering communication beyond geographical borders and preventing physical constraints. Technological developments will also cause social and economic concerns, since they can create mass unemployment, inequality or talent shortages. In response to these foreseen working modifications, workers must be prepared to communicate digitally in a common language, known as lingua franca, usually English for global digital communications. In such context, local, regional and global communication is normally conducted through digital environments. Thus, as telecollaboration relates to the engagement of geographically dispersed learners in online intercultural exchanges using ICT (information and communications technologies), the potential of such collaborative methodology appears to be particularly promising for the forthcoming Industry 4.0 context, in which over one-third of skills that are considered important in today's workforce will have changed. In order to assess the potential of such collaborative ICT-based learning methodologies to promote digital cooperation networks amongst companies and enterprises, a pilot survey focused on telecollaboration was carried-out in the Portuguese region of Castelo Branco. Preliminary results allowed discussing the advantages of combining such learning methodologies with the digital interconnectivity related to the Industry 4.0 context to develop new strategic avenues of cooperation between regional, national and international actors.
\end{abstract}

Keywords: Telecollaboration, Industry 4.0, English Lingua Franca, Intercultural Communication

\section{Introduction}

\section{What kind of English are you learning?}

In the current globalized era, not everything is global in the economy: in fact, most production, employment, and firms are, and will remain, local and regional (Hardiman 1989), although everybody will be required to learn to communicate at a global scale.

The plurilingual skill to be able to communicate globally is important because the internal dynamics of a networked society reproduces the process of exclusion of a significant proportion of people in the world that are unable to do so(Castells, 2000). Not being able to use a global language implies loss of power. S. Breidbach in Plurilingualism, Democratic
Citizenship in Europe and the Role of English. (Breidbach, 2003) argues that the new globalized society of increased (voluntary and enforced) mobility of people dictates new communicative needs at the level of public encounters, requires plurilingual competences as well as competences to deal with cultural diversity.

Thus, the means and the ways to learn English or any other language as a foreign language for global communication has changed in nature: not only is English not valued as a foreign language anymore, but it has become a lingua franca for communication across the web. This entails two very meaningful changes: one is that being able to communicate in English is taken for granted in the global market; Employers do not ask any more for fluency in English for business purposes; they presume employees know how to do it. Furthermore, 
this tacit assumption that all employees will manage to communicate purposefully in English, increases the value of additional foreign languages spoken by employees.

The other big change is that all the foreign users of English as a lingua franca are complex speakers that require their interlocutors to be able to navigate the cultural complexities of what other speakers are saying in English (Janssen, 1999).

Thus, when planning English courses, language providers have to focus more on developing the intercultural communicative competence of English foreign speakers through exposing them to authentic situations in which they can use English and through which they effectively learn to negotiate complex cultural meanings that may interfere with verbal (spoken and written) communication.

Although all of this may be clear for language providers and linguists, most employers and employees hold fuzzy notions of how to develop communicative skills in English for business purposes; they also rely on methods and models they used to learn and thus rely on old grammar paradigms of learning a language as a set of words, phrases or discourses, or blindly trust the automatic translator to do their lingua-culture translation job, most of the times to very bad end results. Despite claiming that they need to speak, write and use English for very specific technical, communicative or intercultural purposes, when asked about their intentions to perfect those skills on the job, employers and employees give contradictory answers and seem to prefer traditional ways of learning a language, face-to-face in a classroom and once or twice a week. However, there are currently methods to perfect communicative skills in English that can be introduced on the job and be tailor-made for specific needs.

This paper thus integrates responses to a survey conducted in a region in Portugal to employees to measure their needs, but also their awareness of forthcoming needs in what concerns their plurilingual skills (here focusing on English), with results from a European-funded project (ICCAGE) in order to discuss how best to communicate linguistic needs to industry 4.0 employers and employees and offer them efficient learning solutions that are technology-enhanced and blended (face-to-face and digital), besides creating opportunities for authentic uses of English.

\section{What do employers need?}

An international survey conducted by Erasmus+ funded project ICCAGE (Intercultural Communicative Competence: an advantage for global employability; Project nr. 2015-1-CZ01-KA203013992) was conducted among European employers in Portugal, Spain, Hungary and the Czech Republic, by staff from Instituto Politécnico de Castelo Branco
(IPCB), Portugal, Ceské Vysoké Ucení technické v Praze (CTU), Czech Republic, Budapest Business School (BBS), Hungary and Universidad de León (ULE), Spain.

Employers were asked to respond to 6 topics on intercultural diversity and intercultural contacts in their companies, problems or misunderstandings at work due to cultural difference, intercultural competence needed and readiness of higher education students to work in international contexts.

Results show that besides language skills (being fluent in English), there are great expectations regarding both general intercultural communicative skills and those that are more intimately connected to learning a foreign language (be it English, Spanish or any other). As general skills, employers pinpointed the following: showing respect for others, being culturally sensitive, being aware of diversity, curious and showing empathy and tolerance; possessing self-critical awareness and the willingness to review own experience and knowledge continuously.

Among the expected language-related skills mentioned by employers, such as sound knowledge of the foreign language, social interaction was highlighted as a field of particular significance whereby employees should evolve into a higher knowledge of the other's cultural needs. Employers were also sensitive to verbal and non-verbal communication skills needed, the ability to resolve cultural conflict and finally, awareness of diversity in time management, working styles, etc.

As preliminary data for updated training to be carried out in the working space or complementary to the needs of employees, these findings legitimize plurilingual learning as the learning of linguacultures and the development of specialized vocabularies for each area of work in connection with highly contextualized role-plays on authentic communicative situations.

\section{Introducing telecollaboration}

A summary of baseline approaches to teaching intercultural communicative competence and a foreign language simultaneously, arrived at through research-based (Baños, 2008; Byram, M. and Zarate, 1994; Byram, 1997; Dooly, 2006; Glaser, E., Guilherme, M., García, M. C. M. and Mughan, 2007; Gonzalez Piñero, M., Díaz, C. G., Vez, 2010; Guilherme, 2012; Holliday, A., Hyde, M. and Kullman, 2004; Lewis, 2002; Liddicoat, A. J. and Scarino, 2013; Nikleva, 2012; Sarmento, 2015; Teixeira, 2013; Trompenaars, F. \& Hampden-Turner, 1998; Trompenaars, F. \& Wooliams, 2003; Utley, 2004) and inquiry-based research by the ICCAGE partnership highlights the need for students of a foreign language to be able to use it for authentic purposes. This could be done through some type of online collaboration (such as telecollaboration), given the facility of web- 
based learning available, but also through scenario building, critical incidents to solve or experiential learning.

In this paper we will present the advantages of telecollaboration. As described in the Final Transnational Report of the ICCAGE project (Morgado et al 2016 not published), telecollaboration is the activity of engaging learners in online communicative activities together through a series of collaborative tasks, accompanied by a series of videos and links to connected materials. Telecollaborative exchanges run through a couple of weeks and generally comprise a first stage, where participants introduce themselves to one another, a second, in which they contrast some aspects of their work, and a third stage where they develop a project together. The advantages for on the job training in authentic uses of English are innumerable, as learners are actually engaged in meaningful communication with other learners who are geographically distant and can experience the difficulties and problems of communicating with other speakers first hand, while being invited to find solutions to the difficulties encountered.

Telecollaboration in learning a foreign language develops basic interpersonal communicative skills for distance communication, where non-verbal supports are missing, while embedding language in meaningful supportive contexts (Baker, 2006).

\section{Methodology}

This study utilized a self-developed questionnaire to carry out a pilot survey in the Portuguese region of Castelo Branco. The information related to the development of the survey questionnaire followed a previous study on the perception of English language skills, as well as the communicative events, in which English was mostly used by the local workforce in the same Portuguese region (Régio, Gaspar, Farinha, \& Morgado, 2016). Current study focused mainly on the digital interconnectivity and the work-related aspects in which local workers perceived the need to improve their intercultural communication skills in English.

The short questionnaire's structure presented six main questions with some sub-questions, in which the respondents were allowed to complement with their own words and ideas some of the inquired topics. Even though several complementary data collection methods might have been used in current pilot investigation (Yin, 2009), namely qualitative research interviews (Robson, 2002), due to the exploratory nature of the research, a pilot study seems to be more adequate as it allows preliminary analysis of the survey questionnaire to be used in a future broader study.
A total of 50 questionnaires in Portuguese language were conducted in diverse public, industrial and service driven enterprises within the Region of Castelo Branco. Data were collected at the interviewees' workplaces based on physical paper questionnaires delivered on location. Such questionnaires were later processed without complementary feedback from the respondents. Fifteen entities were selected amongst local enterprises, namely five public entities and ten private companies. Public entities were related to local administration, to innovation, and to education.

In what refers to private companies, a range from agricultural producers to industrial companies, as well as commercial and service providing companies were selected. On what refers to the size of such enterprises, the total number of employees ranged from 1 to approximately 600. After transcribing the interviews into English, the responses were coded and further analysed.

\section{Results}

Considering Castelo Branco's local workforce digital interconnectivity and web-based communication resources, the respondents referred that $96 \%$ had access to the internet in their workplace. Nonetheless, from such universe, only $58 \%$ mentioned having also microphone, webcam and loudspeakers.

\section{- Use of English at the workplace}

In what concerns the use of English related to their work tasks, $54 \%$ of the interviewees mentioned they read technical manuals, whereas $42 \%$ refer that they use technical instructions in English within their working environment. Half of the interviewees also referred that they needed English to communicate with their enterprise's visitors and customers.

- Improving English communication skills of work groups

When questioned about the desire to improve their own communication skills in English (considering their workplace tasks), 17\% showed no desire to further improve their language skills, whereas $40 \%$ mentioned their availability to participate in face-to-face learning sessions, $19 \%$ in mixed online and face-to-face sessions and $23 \%$ in exclusively online learning sessions.

When questioned about whether the remaining individuals of the work teams they led and/or are part of would be interested in further developing their work-related English language communication skills, $40 \%$ mentioned that other team elements would certainly be willing to participate in such learning classes. As to the periodicity of such classes, 
$73 \%$ of the interviewees claimed to be interested in once a week three hour sessions, whilst 23\% referred their interest in having two weekly sessions. The remaining $3 \%$ mentioned their preference for alternative two days' intensive programs. Finally, considering that such session would take approximately three hours each, $58 \%$ of the respondents stated that six weeks would be the ideal duration of the classes, 38\% mentioned eight weeks and $9 \%$ referred ten weeks.

\section{Preliminary Findings Discussion}

One of the main characteristics related to Industry 4.0 is the digital interconnectivity allowed by current technology, based on recent ICT developments.

As a result, new challenges, as well as new opportunities are expected to take place in such digital landscapes, demanding from current and future workers the ability to adapt and grow in such ground-breaking digital-based interconnected environments to promote effective and efficient cooperation networks and continue to learn and update own learning.

When considering the design principles for Industry 4.0 scenarios, plurilingual skills are highlighted as one of the main principles to guarantee the Interoperability of Industry 4.0 (Hermann, Pentek, \& Otto, 2016). In this context, multilingualism means that Industry 4.0 should support multiple languages for effective delivery of information and knowledge in cyber physical systems (Lu, 2017). Thus, the ability to communicate amongst workers using digital resources to promote effective and efficient cooperation networks is a key issue on which to plan in-service linguistic programs that should also take into consideration the basic skills workers already possess, their perceptions on how they learned foreign languages and suggestions on web2.0 and web3.0 technologies to enhance learning.

To this end, it is important for language providers to facilitate telecollaboration in the workplace as a learning methodology that supports intercultural communicative learning and authentic uses of languages that are being learnt. The affordances of Web 2.0 allow for a variety of customized tasks to be developed through online virtual exchanges that may focus on the types of interaction required for each company. The completion of online tasks by learners that have been paired up and have to meet online to perform that creates opportunities for on the job learning and authentic uses, while allowing individuals to reinforce their own understandings and to face new communicative challenges in an online environment that is monitored by an e-tutor.
Telecollaborative tasks can be so designed as to foster accuracy, fluency and any degree of complexity of meaning/form of communication in order to guide learners in developing either discourse, vocabulary, grammar or all functions of the foreign language, progressively, while promoting collaborative knowledge construction and usergenerated knowledge (Carloni, 2013), which is of paramount importance for employers and on the job learning.

One further aspect that promoters of webbased telecollaboration (Guth, Helm, \& O’Dowd, 2014), or virtual online exchanges, have repeatedly highlighted is the integrated learning of using a foreign language authentically and the development of information management skills. The latter are developed twofold, through familiarization with the tools and digital platforms and apps the learners use to telecollaborate (which might be customized by companies themselves), but also through the acquisition and development of new skills required for the 21st work environments, such as the digital research and information fluency skills described by the International Society for Technology and Education (ISTE) (Carloni, 2013), which comprise: guided inquiry, selecting, processing and managing diverse sources and media, evaluating information sources and digital tools for specific end uses, and data processing and reporting results.

Considering the preliminary findings derived from the global universe of the current pilot survey, it is possible to conclude that almost every worker had access to the internet at their workplace, but were perhaps not familiar with web-based learning strategies. This needs to be further researched. Nonetheless, only approximately half of them referred to having cumulatively access to Web 2.0 communication tools, namely to a webcam, a microphone and to loudspeakers. This may be due to lack of information on how these might be harnessed for online learning.

When considering their working tasks, the need of English to read and for technical purposes, such as following or writing technical guides or and procedures was referred by roughly half of the respondents, namely $54 \%$ and $42 \%$ of the total. This shows that even today, local workers need such language skills to operate and function in nowadays enterprises/workplaces. This entails development of multilingual specialized vocabularies to be developed through corporate glossaries; content curation tools that are used as resource aggregators (Carloni, 2013); networked content that can be distributed inside companies and global/local cultural awareness tasks that will facilitate the understanding and the reflection on different behavior, work cultures or values.

Concerning the needs of employers in terms of English to carry-out and operate computer-based 
tasks, software updates were the most referred tasks (48\%), followed by the need to read and write formal and informal e-mails $(34 \%, 24 \%)$ and, finally, the need of English to communicate via web-based videoconferences, which was referred by only one in seven of the interviewees. These needs are easily transferrable into telecollaborative tasks in language learning through simulation.

Only 16\% claimed to need English for telecollaborative tasks, as part of common projects they are developing with foreign organizations, whilst 14\% referred they needed English to analyze written proposals; $10 \%$ of the respondents use such skills to write proposals. This allows us to conclude that even though workers are aware of the need to improve their English intercultural communication skills, they may not be totally aware of the future challenges and demands of the forthcoming industrial revolution; neither are they familiar with new digital modes of learning that can be developed on the job and are less time-consuming and cheaper solutions to traditional language courses.

As a conclusion, further research is needed to validate this pilot investigation, broadening the research to a wider public, i.e., to more companies and to a larger base of activities among local regional economic activity. Further research is also needed on employers and employees' expectations on learning foreign languages on the job and through digital technologies and telecollaboration. As such, crossing these findings among a larger base of results may allow identification of prospective advantages regarding the challenges foreseen to the local entrepreneurial ecosystem by the change of events expected with the forthcoming new industrial revolution in what regards multilingual skills and the models of training that may best suit it.

\section{References}

[1] Baker, C. (2006). Foundations of Bilingua Education and Bilingualism. Clevedon: Multilingual Matters.

[2] Baños, R. V. (2008). La competencia comunicativa intercultural. Un estudio en el primer ciclo de la Educación Secundaria Obligatoria. Retrieved from

http://dialnet.unirioja.es/servlet/libro?codigo=3 78234

[3] Breidbach, S. (2003). Plurilingualism, Democratic Citizenship in Europe and the Role of English. Reference Studies, 2004(12/09). Retrieved from http://www.coe.int/T/E/Cultural_Cooperation/education/Languages/Language_Polic y/Policy_development_activities/Studies/Breidb achEN.pdf?L=E

[4] Byram, M. and Zarate, G. (1994). Définitions, objéctifs et évaluation de la compétence socio- culturelle. Strasbourg: Report for the Council of Europe.

[5] Byram, M. (1997). Teaching and assessing intercultural communicative competence. Assessment. http://doi.org/Brich Library of Congress

[6] Carloni, G. (2013). Content and Language Integrated Learning: A Blended Model in Higher Education. The International Journal of Technology, Knowledge and Sociaeyy, 9, 61-71.

[7] Castells, M. (2000). The Rise of the Network Society Vol. 1: The Information Age: Economy, Society and Culture. Oxford: Blackwell. Retrieved from papers://33432778-ef7b-4391-ae67220f9c46620d/Paper/p3771

[8] Dooly, M. (2006). Integrating Intercultural Competence and Citizenship Education into Teacher Training: a Pilot Project. Citizenship Teaching and Learning, 2(1), 18-30.

[9] Glaser, E., Guilherme, M., García, M. C. M. and Mughan, T. (2007). Intercultural competence for professional mobility.

[10] Gonzalez Piñero, M., Díaz, C. G., Vez, J. M. (2010). Didáctica de las lenguas modernas. Competencia plurilingue e intercultural. Editorial Síntesis.

[11] Guilherme, M. (2012). Critical Citizens for an Intercultural World: Foreign Language Education as Cultural Politics, (66 OP-Revista Crítica de Ciências Sociais, Iss 66, Pp 181-184 (2012)), 181. Retrieved from http://search.ebscohost.com/login.aspx?direct $=$ true $\&$ site $=$ eds -

live \&db=edsdoj\&AN=edsdoj.47554e5bda94673 8d04ef673d103c4a

[12] Guth, S., Helm, F., \& O’Dowd, R. (2014). Telecollaborative Foreign Language Networks in European Universities: A Report on Current Attitudes and Practices. Bellaterra Journal of Teaching \& Learning Language \& Literature, $7(4), 1-14$.

[13] Hermann, M., Pentek, T., \& Otto, B. (2016). Design principles for industrie 4.0 scenarios. Proceedings of the Annual Hawaii International Conference on System Sciences, 2016-March, 3928-3937. http://doi.org/10.1109/HICSS.2016.488

[14] Holliday, A., Hyde, M. and Kullman, J. (2004). Intercultural Communication. An Advanced Resource Book. New York: Routledge.

[15] Janssen, H. (1999). Linguistic dominance or acculturation - problems of teaching English as a global language. In C. GNUTZMANN (Ed.), Teaching and Learning English as a Global Language (pp. 41-55). Tübingen: Stauffenburg Verla.

[16] Lewis, R. (2002). The Cultural Imperative: Global Trends in the 21st Century. London: Nicholas Brealey Publishing. 
[17] Liddicoat, A. J. and Scarino, A. (2013). Intercultural Language Teaching and Learning. Chichester: Wiley-Blackwell.

[18] Lu, Y. (2017). Industry 4.0: A Survey on Technologies, Applications and Open Research Issues. Journal of Industrial Information Integration. http://doi.org/10.1016/j.jii.2017.04.005

[19] Nikleva, D. G. (2012). La Competencia Intercultural. | Cuaderno Intercultural, 25, 165187. Retrieved from http://www.cuadernointercultural.com/lacompetencia-intercultural/

[20] Régio, M. M. A., Gaspar, M. R. C., Farinha, L. M. C., \& Morgado, M. M. A. P. (2016). Forecasting the disruptive skillset alignment induced by the forthcoming industrial revolution. Romanian Review Precision Mechanics, Optics and Mechatronics. Retrieved from http://www.scopus.com/inward/record.url?ei $\mathrm{d}=2-\mathrm{s} 2.0-$ 84979554747\&partnerID=MN8TOARS

[21] Robson, C. (2002). Real World Research. 2nd. Edition. Blackwell Publishing. Malden. Retrieved from http://www.dem.fmed.uc.pt/Bibliografia/Livro s_Educacao_Medica/Livro34.pdf
[22] Sarmento, C. (2015). Estudos Interculturais Aplicados. Textos, Turismos e Tipologias. Porto: Vida Económica.

[23] Teixeira, A. P. (2013). TESE DE DOUTORAMENTO O Desenvolvimento da Competência Comunicativa Intercultural na aula de PLE : Representações e práticas (inter ) culturais . Um estudo de caso.

[24] Trompenaars, F. \& Hampden-Turner, C. (1998). Riding the Waves of Culture: Understanding Diversity in Global Business. New York: McGraw-Hill.

[25] Trompenaars, F. \& Wooliams, P. (2003). Business across Cultures. West Sussex: Capstone Publishing Ltd.

[26] Utley, D. (2004). Intercultural Resource Pack 5. Intercultural Communication Resources for Language Teachers. Cambridge: Cambridge University Press.

[27] Yin, R. K. (2009). Case Study Research: Design and Methods. Essential guide to qualitative methods in organizational research (Vol. 24). http://doi.org/10.1080/09500790.2011.58231 7 